\title{
Numerical Study of Complex Turbulent Flow through Valves in a Steam Turbine System
}

\author{
X. Du and S. Gao
}

\begin{abstract}
One of the main contributions that affect the efficiency of a turbine system is due to the pressure loss through the flow control valves. In this project a three valves system, which includes a stop valve and two governing valves connected by pipes between the boiler and the turbine, has been analysed using a three-dimensional Computational Fluid Dynamics (CFD) model. The main aim is to understand the complex flow through this complex configuration system under different operation conditions, so as to derive the necessary information for optimising the valve designs and the efficient operations of the whole turbine system. Three turbulence models are employed to perform the simulations and detailed results such as the pressure field, velocity field and distributions of the turbulence quantities are carefully analysed. It is found that the standard $k$ - $\varepsilon$ model has produced the best predictions for this flow system. For the pressure loss analysis approximate calculations in each part of the valve system have also been carried out using simplified pressure loss models to testify the simulation results. The comparisons between the approximated loss coefficients and the predicted CFD results have shown reasonable agreements.
\end{abstract}

Index Terms-CFD, pressure loss, turbine system, turbulent flow, valve.

\section{INTRODUCTION}

For a turbine system the operation efficiency is of great importance. There are many factors that can influence this efficiency, and in this project the effect on pressure loss in a three valves system that is located between the boiler and the turbine to control the mass flow rate in the turbine system, as shown in Fig. 1, has been analysed. For such a complex combination that appears in the middle of a turbine system the measurement of some leading parameters is both challenging and very expensive to be conducted. Therefore, a prediction method is necessary to be employed and CFD simulation is an ideal choice for such work.

It is well known that steam is such a complicated fluid that it can have several different forms: wet steam, saturated steam and superheated steam. In this study superheated steam is used and the flow is assumed to be steady, turbulent and incompressible. Most published work concerns mainly a single valve flow problem or combined with the second phase effect. Mazur and coworkers [1], [2] reported their study of solid particle bearing steam flow through the main stop valve in a steam turbine using a 3D model and the FLUENT software, and they concluded that numerical simulation could be really used in a predictive manner.

Manuscript received January 7, 2013; revised March 18, 2013.

X. Du and S. Gao are with the Department of Engineering, University of Leicester, Leicester, LE1 7RH, UK (e-mail: sg32@le.ac.uk)
Advanced CFD techniques and improved computing power have made it possible to simulate more complex flows [3], [4].

The main focus of this research is on the prediction of the actual flow structures and the pressure loss analysis, so that the efficiency of the valve system can be improved by optimising the geometry designs to reduce pressure loss. Three turbulence models: standard $k-\varepsilon$ model, realizable $k-\varepsilon$ model and Spalart-Allmaras model have been employed for the simulations and results comparison. The loss coefficients through different parts of the system have been calculated approximately according to some empirical equations and experimental diagrams as described in [5] and [6], which can serve as useful validation comparison with the CFD predictions.

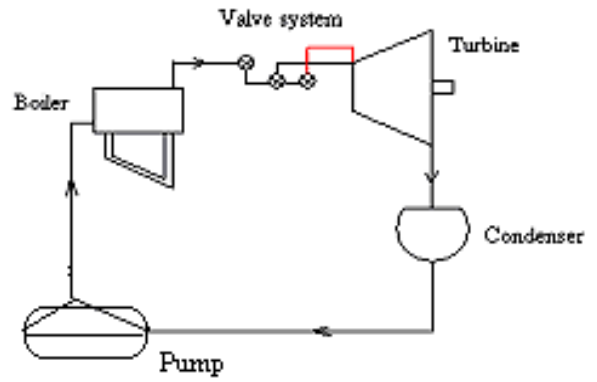

Fig. 1. Schematic diagram of the turbine system.

\section{NUMERICAL METHOD}

\section{A. Geometry and Mesh}

The simulated system includes three valves (one stop valve and two governing valves) and a three-dimensional pipe that connects the valves with the boiler and the turbine, as shown in Fig. 2. The condition reported here is that all the three valves are fully open.

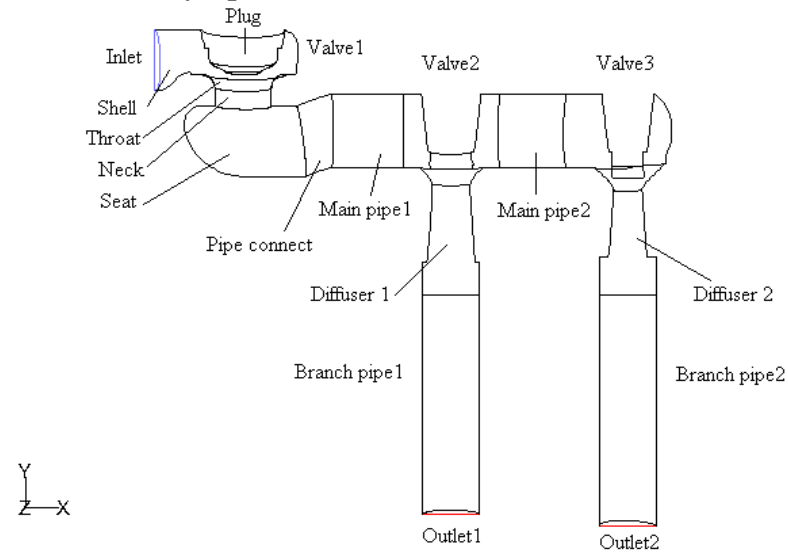

Fig. 2. Geometry of the valve system. 
The software GAMBIT is used for the mesh generation. The whole geometry is divided into different volumes, which can be meshed separately. Some volumes have complicated geometry and various methods can be used to mesh them. The first valve (stop valve), as shown in Fig. 2, includes a number of volume parts such as shell, throat, neck and seat. Shell has a complex shape and needs meshing with Tet/Hybrid elements. The volume part next to it is the throat which is meshed with cooper scheme and shown in Fig. 3 as an example. It can be seen that there are more grids near the wall on source faces and on the wall face grids are uniform.

The whole system is meshed with due considerations and appropriate methods. The schematic diagram of the meshed geometry is shown in Fig. 4.

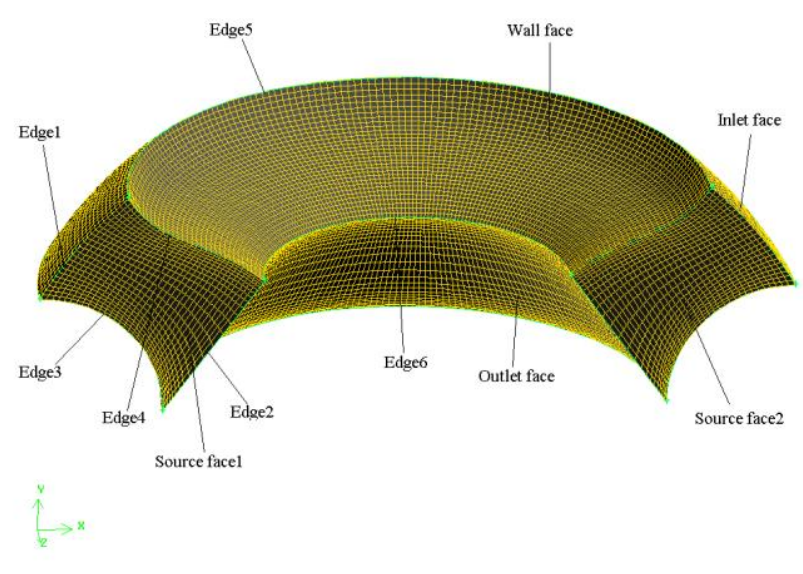

Fig. 3. Computational grid of the throat of valve 1 .

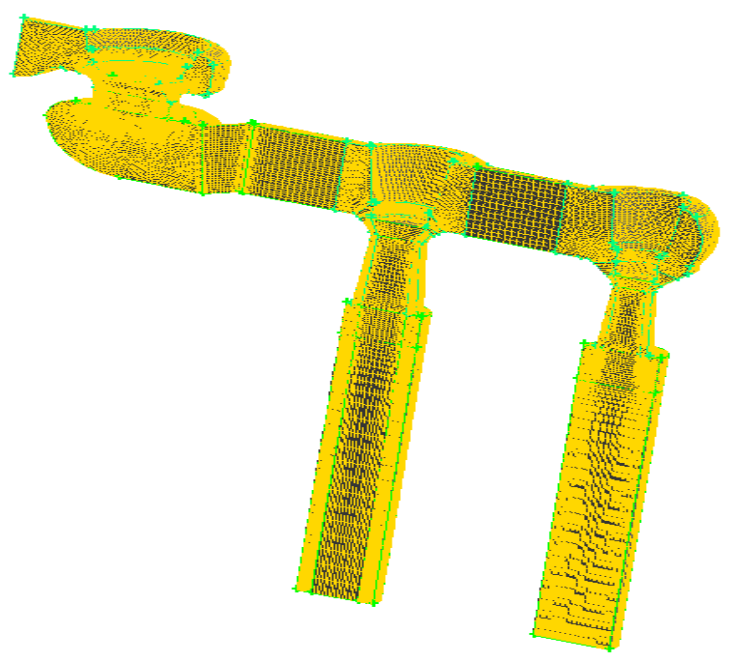

Fig. 4. Mesh structures of the flow system.

\section{B. Turbulent Models}

To predict the turbulent flow an appropriate model needs to be employed, which is known as turbulence modelling. There are many different turbulence models, which can be categorised by the number of transport equations for the turbulence quantities being used in the model. The most popular turbulence models for engineering calculations are the so-called two-equation models, in which two separate transport equations are solved to determine the length and the velocity scales for the eddy-viscosity [10]. FLUENT provides following turbulence models: $k-\varepsilon$ models (Standard, Renormalization-group, Realizable), $k$ - $\varpi$ models (Standard, Shear-stress transport), Spalart-Allmaras model, Reynolds stress model and Large eddy simulation (LES) model. The Spalart-Allmaras (S-A) model, standard $k-\varepsilon$ model and realizable $k-\varepsilon$ model are selected for the prediction and the results are compared with these three models. All the model constants have used the standard default values as defined in FLUENT [12].

\section{Numerical Solver}

Two numerical solution schemes are available in FLUENT: segregated solver and coupled solver. Using segregated solver the governing equations are solved sequentially. The coupled solver solves the governing equations of continuity, momentum, energy and species transport simultaneously [13]. For this problem the segregated solver is used for all the simulations. Second-order upwind scheme is applied to the discretization of the momentum and other turbulence equations. Three methods for pressure-velocity coupling are provided in the segregated solver: SIMPLE, SIMPLEC and PISO. In this project the default SIMPLE solver is selected. The standard wall function is selected automatically to deal with the near-wall treatment.

The inlet of this flow system is defined as Pressure Inlet. The Gauge Total Pressure is defined as $P_{0}=1.34 \times 10^{7} \mathrm{~Pa}$. At the inlet the Reynolds number of the flow is defined as $\operatorname{Re}=3 \times 10^{7}$, so the turbulence intensity, which is defined as the ratio of the root-mean-square of the velocity fluctuation $u$ to the mean flow velocity $u_{\text {avg }}$, can be estimated from [14]:

$$
I=\frac{u^{\prime}}{u_{\text {avg }}} \cong 0.16(\operatorname{Re} \cdot D)^{-1 / 8}
$$

and a value of $1.8 \%$ is used in the simulations. The fluid is defined as water-vapour, with density $\rho=40 \mathrm{~kg} / \mathrm{m}^{3}$ and dynamic viscosity $\mu=2.85 \times 10^{-5} \mathrm{~N} \cdot \mathrm{s} / \mathrm{m}^{2}$.

There are two pressure outlets, outlet 1 and outlet 2 with same Gauge Pressure, which is in fact the static pressure defined as $P_{s}=1.2864 \times 10^{7} \mathrm{~Pa}$. Backflow turbulence intensity and backflow viscosity ratio are given by $10 \%$ and 100,000 , respectively. These backflow values will be used only if backflow does appear in the process of solution. Even if no backflow is expected in the converged solution realistic values still should be set to minimise convergence difficulties in the event that backflow does occur during the calculation procedures [14].

\section{RESUlts AND ANALYSIS}

\section{A. Flow Structure Analysis}

It is helpful to view firstly the flow structure inside the flow system in order to properly understand other results. Plots of path lines from different turbulent models are very 
similar. As an example some results from the standard $k$ - $\varepsilon$ model are presented here. From Fig. 5 it is clear that flow recirculation exists inside spheral chamber (the seat) at the bottom of valve 1 , and a secondary flow happens when the flow enters the neck pipe from the 'right' side of the plug (around the plug).

Fig. 6 shows that a strong secondary flow happens in valve 2 , which will lead to unstable flow in branch pipe 1 and make a big contribution to the pressure loss in valve 2 . From the path lines shown in Fig. 7 it is clear that the flow is more uniform in valve 3, which suggests that the flow in branch pipe 2 is more stable. This has been confirmed by the nearly uniform path lines in branch pipe 2 (not shown here).
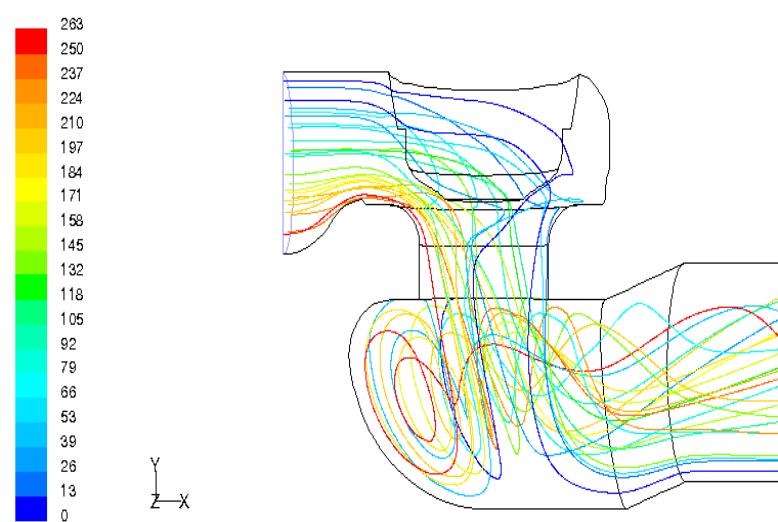

Fig. 5. Path lines of particles released at the inlet of valve 1 .
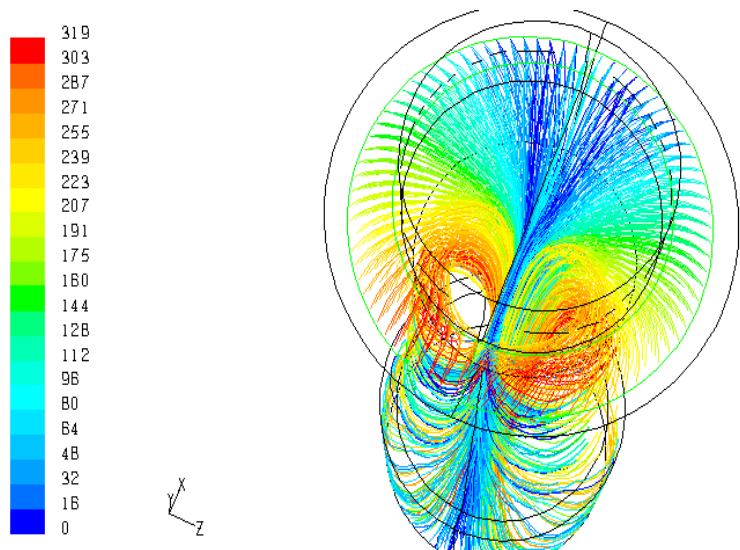

Fig. 6. Path lines showing strong secondary flow in Valve 2.
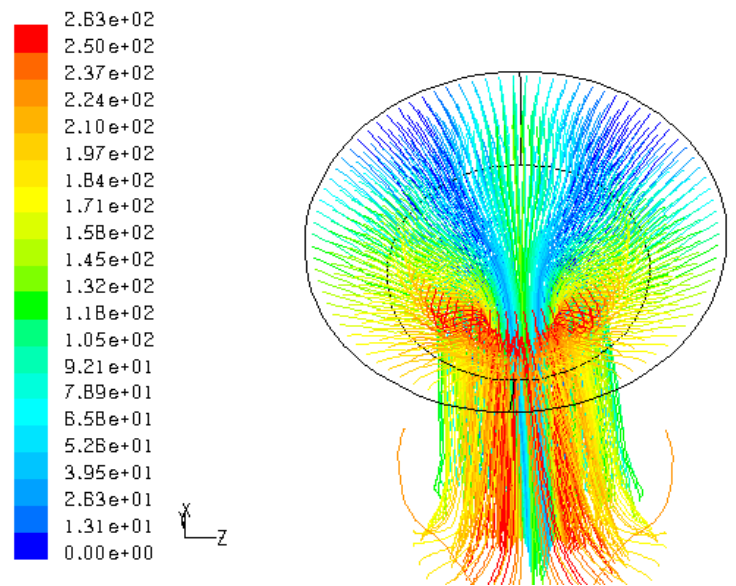

Fig. 7. Path lines showing more uniform flow in Valve 3.

Fig. 8 shows that the static pressure decreases when steam flows through the throat of valve 1 because the throat is a contractive part, which will accelerate the flow. Then steam flows into the main pipe where no big change of the geometry exists so the static pressure has not changed evidently. Through valves 2 and 3 there are two branch pipes that have diverged the flow into them. Clearly the flow is accelerated greatly at the two inlets (see also Fig. 10 and Fig. 11) and this leads to the heavy drop in the static pressure. After this the flow passes the two diffusers, which give a slow recovery of the static pressure. It is seen that the pressure is roughly kept at the same level in each smooth branch pipe.
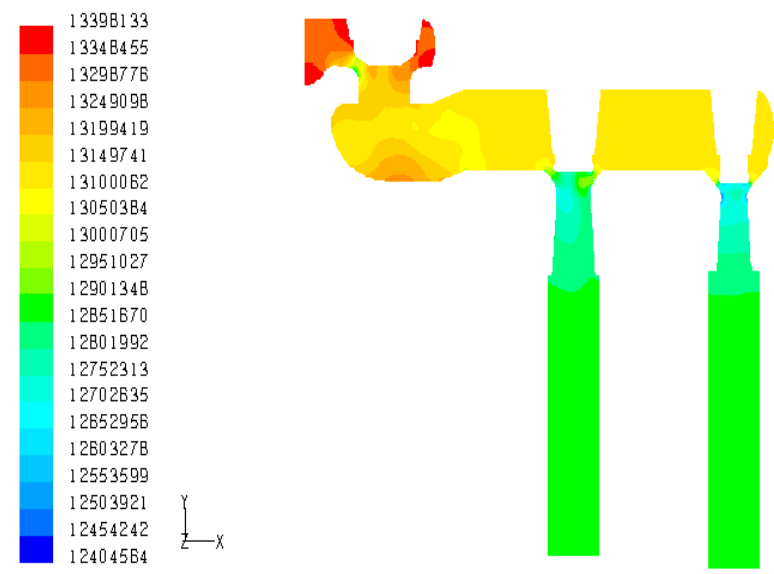

Fig. 8. Static pressure distribution with standard k- $\varepsilon$ model.
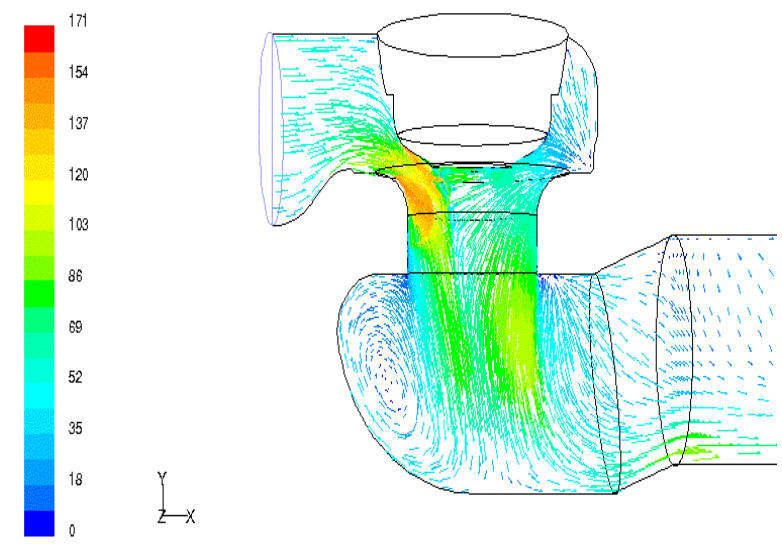

Fig. 9. Velocity vectors in valve 1.

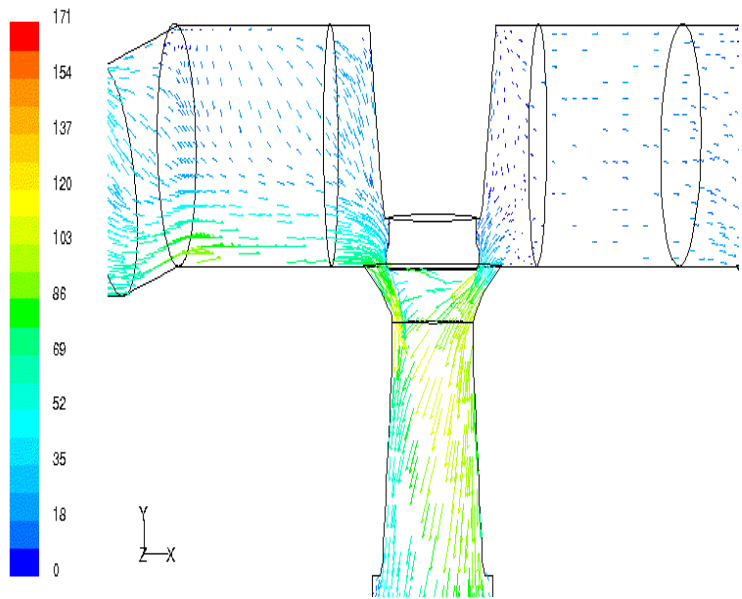

Fig. 10. Velocity vectors in valve 2 .

The main difference of the $k-\varepsilon$ model prediction from the other two turbulent models is in the pressure drop after the inlet of valve 2 . The results from the S-A model show a clear non-uniform pressure drop because the effect of the secondary flow is considered by this model. The 
non-uniformity of velocities results in the non-uniform static pressure drop. The results from the realizable $k-\varepsilon$ model also show the similar effect.

The flow structures can also be examined by viewing the velocity vectors as shown in Fig. 9-Fig. 11 from the standard k- $\varepsilon$ model. It can be seen that for valve 1 there exists strong flow recirculation. The secondary flow in valve 2 and a relatively uniform flow in valve 3 are also evident.

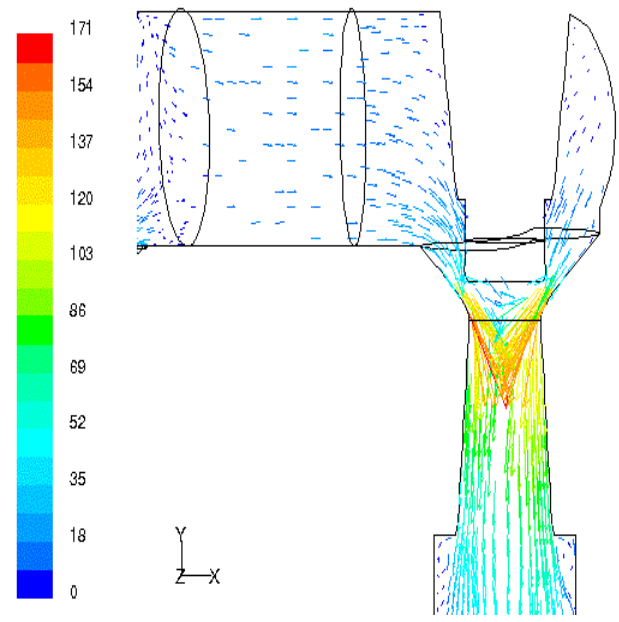

Fig. 11. Velocity vectors in valve 3 .

\section{B. Pressure Loss}

The total pressure loss can be generally regard as the sum of the main loss due to the frictional effects in fully developed flow in constant-area tubes, and the local loss due to entrances or fittings area changes. For this valve system obviously the local loss plays a leading role. Turbulence is responsible for the majority of the local pressure losses. The pressure variations from the inlet to outlets at some important cross sections, as shown in Fig. 12, are computed from the FLUENT standard k- $\varepsilon$ model, and the results are presented in Fig. 13. It can be seen that the total pressure has a large loss in the following regions: 1-2 (from position 1 to 2), 2-3, 4-5 and 4' -5 '. The maximum total pressure loss of the system is $5.21 \times 10^{5} \mathrm{~Pa}$, between Inlet and Outlet2. The mass flow rates are $54.64 \mathrm{~kg} / \mathrm{s}$ at Inlet, $32.41 \mathrm{~kg} / \mathrm{s}$ at Outlet 1 , and $22.23 \mathrm{~kg} / \mathrm{s}$ at Outlet2, respectively. Therefore, the flow split is: Outlet1 shares $59 \%$ and Outlet 2 has $41 \%$.

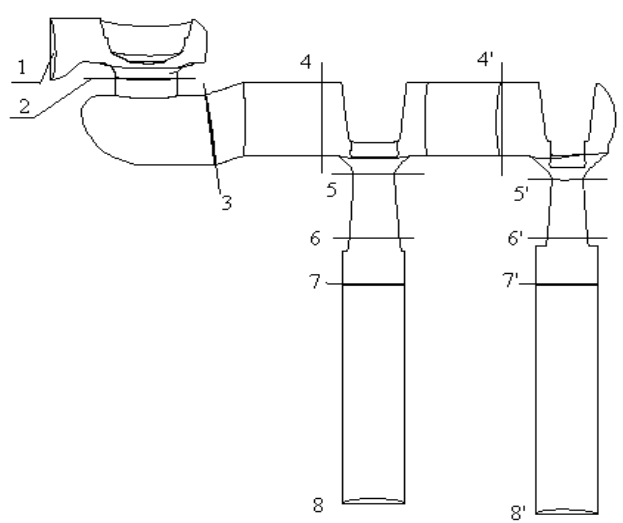

Fig. 12. Pressure surface specification at selected locations.

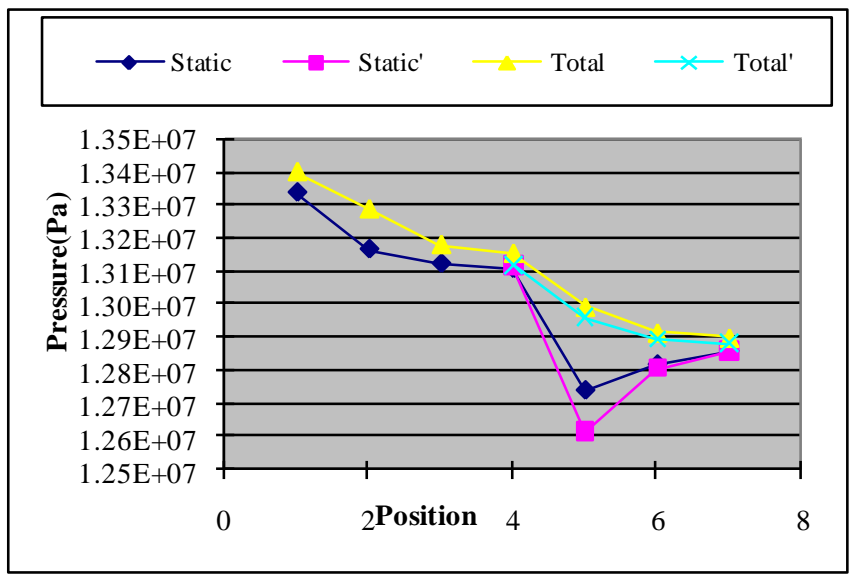

Fig. 13. Pressure variations at selected regions.

Detailed pressure loss calculations using published experimental curves for simplified geometries [5], [6] are also conducted at the selected regions and the results are compared in Table 1 with those obtained from the FLUENT standard k- $\varepsilon$ model, as an example. The loss coefficient $K$ is defined as

$$
K=\frac{\Delta H}{U^{2} / 2 g}=\frac{\Delta P}{\rho U^{2} / 2}
$$

where $\Delta H$ is the total head loss, and $\Delta P$ the total pressure loss.

TABLE I: PRESSURE LOSS COMPARISONS IN THREE REGIONS

\begin{tabular}{|c|c|c|c|}
\hline & $\begin{array}{c}\text { Experimental } \\
\text { approximations }\end{array}$ & FLUENT & $(\%)$ \\
\hline Region 1-2 & 2.75 & 2.33 & -15 \\
\hline Region 2-3 & 0.92 & 0.97 & +5.4 \\
\hline Region 4-5 & 5.10 & 5.26 & +4.3 \\
\hline
\end{tabular}

It can be seen the comparisons between the two approaches are reasonably close. Region 4'-5' has almost the same structure with region 4-5, therefore, the loss coefficient in this part is not included in Table 1 . The above analysis has shown clearly that the geometries in those four regions lead to big pressure loss for this flow system. The system efficiency can be improved by optimising the geometries of those parts.

Region 1-2 is basically a step on the plug, which causes a big effect on pressure loss and can be eliminated. The bottom of this region produces strong flow separation, as discussed earlier, and this part can be made into a longer converging nozzle to reduce the separation effect. Obviously in region 2-3 the sudden expansion from the inlet to the big spherical chamber results in big pressure loss. This may be improved by adding an arc on the connection part between the inlet tube and the seat of valve 1 . Furthermore, the size and shape of the seat can also be reconsidered. For regions 4-5 and 4' -5 ' the steps on the plug also make contribution to the whole pressure loss. But the major pressure loss is caused by flow changing direction and this effect needs to be reduced. For example, the inlet of the converging nozzle may be made wider. Apparently the pressure losses in regions 5-7 and 5' -7' 
(see Fig. 12) are mainly due to the diffusion and sudden expansion effects. Each of the two parts is composed of a diffuser and a step, and they can be improved by an optimised pipe design and a rounded smooth step to reduce the pressure loss.

\section{CONCLUSION}

All the CFD simulations have been carried out using the software package GAMBIT and FLUENT. The computational models have been carefully constructed and meshed using GAMBIT, and then subsequently solved by the FLUENT solver. Successful simulations have been carried out by employing three widely used turbulence models: the one equation Spalart-Allmaras model, the two equations standard k- $\varepsilon$ model and realizable k- $\varepsilon$ model. Detailed results such as the pressure field, velocity field and distributions of the turbulence quantities are analysed and compared with the different turbulent models, though only some selected results are presented in this paper. It is found that overall the standard k- $\varepsilon$ model has produced the best predictions for this flow system and the results from this model are recommended for further valve design improvements.

To ensure the reliability of the simulations, detailed code validations and grid independence tests have been conducted prior to the production simulations reported in this paper. For the pressure loss analysis approximate theoretical calculations in each part of the valve system have also been carried out using a simplified pressure loss model to testify the simulation results. The comparisons between the approximated loss coefficients and the predicted CFD values have shown reasonable agreements. Moreover, the CFD predictions have produced detailed flow structures and demonstrated CFD as a powerful tool for analysing complex industrial flows.

\section{ACKNOWLEDGMENT}

We are most grateful to the invaluable advice and assistance from Dr J. Chen on this project.

\section{REFERENCES}

[1] Z. Mazur, R. Campos-Amezcua, G. Urquiza-Beltrán, and A. García-Gutiérrez, "Numerical 3D simulation of the erosion due to solid particle impact in the main stop valve of a steam turbine," Applied Thermal Engineering, vol. 24, pp. 1877-1891, 2004.

[2] Z. Mazur, V. Cristalinas, and J. Kubiak, "The methods of improving and emergency repair of steam turbine main stop valve bypass valve damaged by erosion," in Proc. V Latin American Conference on Turbomachinery, Acapulco, Mexico, 1995, pp. 1-6.

[3] R. W. Lyczkowski, I. K. Gamwo, and F. Dobran, "Validation of computed solids hydrodynamics and pressure oscillations in a model bubbling atmospheric fluidized bed combustor," Powder Technology, vol. 76, no. 1, pp. 65-77, 1996.

[4] R. Simpson and S. Gao, "CFD analysis of a piston-driven transient flow in an IC engine with a generic inlet tract," in Proc. $4^{\text {th }}$ International Conference on Heat Transfer, Fluid Mechanics and Thermodynamics, Cairo, 2005.

[5] D. S. Miller, 1990, Internal Flow Systems, 2nd ed. BHRA, 1990, pp. 21-26, pp. 381.

[6] I. E. Idelchik, Handbook of hydraulic resistance, 2nd ed. Revised and Augmented, Hemisphere Publishing Co., 1986, vol. 164, pp. 361.

[7] A. O. Demuren and R. V. Wilson, "Estimating Uncertainty in Computations of Two-Dimensional Separated Flows," Transactions of the ASME, Journal of Fluids Eng., vol. 116, pp. 216-220, 1994.

[8] D. K. Gartling, "A test Problem for Outflow Boundary Conditions-Flow Over a Backward Facing Step," International Journal for Numerical Methods in Fluids, vol. 11, pp. 953-967, 1990.

[9] O. Reynolds, "On the dynamical theory of incompressible viscous fluids and the determination of the criterion," Philos. Trans. of R. Soc. London, Ser A-186, pp. 123-164, 1895.

[10] G. Biswas and V. Eswaran, Turbulent Flows: Fundamentals, Experiments and Modeling, Alpha Science Int. Ltd, 2002, pp. 24.

[11] FLUENT Inc., GAMBIT 1, Modelling Guide, FLUENT Inc., 1998, pp. 3.1-3.169, pp. 4.1-4.16.

[12] FLUENT Inc., FLUENT 6, User's Guide, vol. 2, FLUENT Inc., 2001, pp. 10.1-10.102.

[13] FLUENT Inc., FLUENT 6, User's Guide, vol. 5, FLUENT Inc., 2001, pp. 22.1-22.140.

[14] FLUENT Inc., FLUENT 6, User's Guide, vol. 1, FLUENT Inc., 2001 pp.6.1-6.107.

[15] J. Boussinesq, “The'orie de le'coulement tourbilaant," Mem. Presente's paar divers savants Acad. Sci. Inst. Fr., vol. 23, pp. 46-50, 1877.

[16] B. Mohammadi and O. Pironneau, Analysis of the K-Epsilon Turbulence Model, John Wiley \& Sons, 1994, pp. 63-78.

[17] W. L. Oberkampf and F. G. Blottner, "Issues in Computational Fluid Dynamics Code Verification and Validation," AIAA Journal, vol. 36, no. 5 , pp. 687-695, 1998.

[18] S. Horsder, B. Grossman, R. T. Haftaka, W. H. Mason, and L. T. Watson, "Remarks on CFD Simulation Uncertainties", MAD Center (at Virginia Polytechnic Institute \& State University) Report, pp. 2-6, 2003.

[19] M. C. Potter and D. C. Wiggert, Mechanics of Fluids, 3rd ed. Brooks/Cole, 2001, pp. 301-302.

[20] A. A. Townsend, The Structure of Turbulent Shear Flow, The Syndics of the Cambridge University Press, 1956, pp. 194-221.

X. Du had his BEng from Xi'an Jiaotong University, China in 2001, MSc from University of Leicester in 2003, and PhD from ENSAM Paris in 2010. His main research interests are in CFD, high order residual based compact (RBC) scheme, aerodynamics, turbulent flow and heat transfer.

S. Gao had his BEng from Petroleum University of China in 1982, and $\mathrm{PhD}$ from Queen Mary College, University of London in 1989. He was a Research Fellow at Queen Mary College and then at University of Surrey from 1990 to 1994, followed by an appointment to a Lectureship in Thermofluids in the Engineering Department of Leicester University. Main research interests are in CFD, focusing on DNS/LES of turbulent flow, multiphase flow and heat transfer, and their industrial applications, such as flow assurance, lubrication, air conditioning, jets, turbomachinery and combustion process. 